\title{
Effects of Vojta Therapy on the Forced Vital Capacity and Forced Expiratory Volume at One Second in Young Male Smokers: A Single-Subject Design
}

Jin Seon Kim¹, Da Young Kim¹, Hee Sun Kim', Si Won Park', Yun Jeong Lee'1, Hyoung Won Lim²

'Department of Physical Therapy, College of Health Science, Student of Dankook University, Cheonan; ${ }^{2}$ Department of Physical Therapy, College of Health Science, Dankook University, Cheonan, Korea

Purpose: This study examined the effects of Vojta therapy on the respiratory function in young male smokers.

Methods: Three subjects were tested using the ABA design for Single-subject Experimental Research Design. This study was conducted with the baseline, intervention, and follow-up phase. Intervention was conducted three to four times a week for 20 minutes per times and a total of 25 sessions. The respiratory function was measured using a Spirometer.

Results: The results of Forced Vital Capacity and Forced Expiratory Volume at one second for all subjects showed improvements in the intervention phase over the baseline phase. In the follow-up phase, the improved ability was still maintained or slightly reduced.

Conclusion: Vojta therapy used on young male smokers was effective in both FVC and FEV1. In other words, the Vojta therapy worked effectively in improving the respiratory function. In future studies, it is necessary to have a control group and increase the number of trials in order to generalize the effect of Vojta therapy.

Keywords: Vojta therapy, Respiratory function, Smoking

서 론

호흡 기능은 인간에게 매우 중요한 기능으로, 호흡은 대사에 필요한 공기 중 산소를 받아들여 대사과정에서 발생한 몸속 이산화탄소를 배출하는 과정이다.1 질병의 가장 일반적인 위험 요인 중 네 번째로 꼽 히는 흡연은 천식이나 만성 폐쇄성 폐 질환(chronic obstructive pulmonary disease, $\mathrm{COPD}$ )과 같은 호흡기 질환부터 심혈관 질환, 뇌졸중 및 폐암을 포함한 여러 암에 이르는 20가지 이상의 질병을 일으킨다. ${ }^{2}$

담배 연기의 성분은 주요 기도에서 말초 폐포까지 면역계뿐만 아 니라 호흡기 전체에 손상을 일으킨다. 연기는 또한 기관지 세포의 염 증을 일으켜 호흡근의 비대 및 기관지 섬유화를 유발한다. ${ }^{3}$ 이로 인 해 공기 흐름의 장애가 발생하고 흡연자의 $25 \%$ 가 $\mathrm{COPD}$ 로 이환되며, 조기에 $\mathrm{COPD}$ 를 진단하지 못하고 계속해서 흡연한다면 폐의 비가역 적인 변화를 막는 데 어려움을 겪을 것이다. ${ }^{5}$

세계보건기구의 최근 연구에서는 전 세계적으로 6 천 5 백만 명이
넘는 사람들이 중등도에서 중증의 $\mathrm{COPD}$ 를 가지고 있다고 보고하였 다. $\mathrm{COPD}$ 는 진행성 폐 질환으로 기침, 객담 배출, 10 년 이상의 호흡곤 란 등의 증상을 호소하며 호흡곤란으로 폐 기능이 감소하고 일상생 활 활동 수행 능력이 저하된다. ${ }^{6}$ 또한, 호흡곤란으로 인한 활동량 감 소는 호흡근의 약화를 초래한다.78

흡연에 대한 이전 연구를 살펴보면 대학생 흡연 및 비흡연 집단의 폐 기능 비교 결과 흡연 집단에서 노력성 폐활량(forced vital capacity, FVC), 1초간 최대 호기량(forced expiratory volume at one second, $\mathrm{FEVl}$ ), 최대 수의 환기량(maximum voluntary ventilation, $\mathrm{MVV}$ )이 낮 게 나타나 폐 기능이 낮은 것으로 보고되었으며,' 20 대 성인 남성의 장 기적인 흡연 집단에서 낮은 유산소 운동능력을 보고하였다. ${ }^{10}$ 다른 연구에서는 30 대 성인 남성의 연구에서도 흡연자가 비흡연자보다 FVC와 FEV1이 유의한 차이로 낮게 나타났으며, ${ }^{11} 15-18$ 세부터의 연 구에서 흡연 집단에서 $\mathrm{FVC}$, 최대 날숨 유량(maximal expiratory pressure, MEP), 가슴 확장 용적(chest expansion)이 낮은 것으로 보고되었 
다. ${ }^{12}$ 이처럼 흡연 집단은 비흡연 집단보다 폐 기능이 현저히 떨어지는 것을 알 수 있다. 폐 기능을 향상시키기 위한 치료에는 호흡 운동, 들 숨 근육훈련, 유산소 운동 등이 실시되고 있다.13,14

반사적 이동 운동(reflex locomotion)으로 알려진 보이타 치료는 피 부 표면에 있는 특정 지점을 지속적으로 자극하여 광범위한 운동 반 응 즉 목, 몸통 및 사지에서 긴장성 근육(tonic muscle) 수축의 비대칭적 인 패턴을 일으킨다.15 최근, 보이타 기전을 뒷받침하는 연구가 보고되 고 있다.15,16 그중 Pontomedullary reticular formation은 직접적인 척수 입력을 받아 신체로의 입출력의 교점을 제공하고 그물 척수로(reticulospinal tract)를 통해 복잡한 운동 반응을 잠재적으로 유도하며 가로 막과 복부 운동 신경 세포와의 억제 연결로 자세 조절 및 비대칭 운동 패턴의 생성에 기여한다. 이는 보이타 치료의 자극 효과와 직접적으로 연관된다.15,17 호흡 기능 개선을 위해 적용한 보이타 치료에 관한 선행 연구로는 보이타의 유발점 자극을 통하여 뇌성마비 아동의 최대 호기 량, FEV1, 흥곽 용적의 양적인 변화를 보고하였고, ${ }^{18}$ 경직형 뇌성마비 아동의 호흡근이 강화되면서 폐활량이 향상되었음을 보고하였다. ${ }^{19}$ 또한, 보이타의 반사적 이동 운동이 경직형 뇌성마비 아동의 발성 능 력의 향상이나 호흡 기능, 호흡근 활성도 증가에 유용하다고 보고하 였다. ${ }^{20}$ 지금까지 보이타 치료 관련 논문은 뇌성마비 아동과 관련된 연 구가 많이 진행되었다. 그러나, 대표적으로 호흡 능력의 저하를 보이는 흡연인구를 대상으로 치료의 효과성을 입증한 연구는 부족한 실정이 다. 따라서 본 연구에서는 20 대 흡연 남성을 대상으로 보이타의 가슴 유발점 자극이 폐 기능에 미치는 영향에 대하여 조사하고자 하였다.

\section{연구 방법}

\section{1. 연구 대상}

본 연구는 충청남도 천안시에 소재한 D 대학교에서 흡연 남학생 3 명 을 대상으로 2018년 10월 29일부터 2019년 1월 19일까지 진행하였다. 대상자들은 통계청에서 보고한 일평균 흡연량인 $12 \pm 3$ 개비의 담배를 5 년 이상 지속하고 있는 자로 하였다. 본 연구의 대상자 선정기준은 다 음과 같다. 1) 심혈관계 및 정형외과적 질환이 없는 자, 2) 폐 기능에 영 향을 미치는 약물을 복용하지 않는 자. 대상자들은 실험 전 실험 과정 에 대해 충분한 설명을 듣고 실험 참여에 자발적으로 동의하였으며, 연구 동의서 작성 후에 연구를 진행하였으며, 연구 기간 동안 흡연량
은 유지되었다. 연구 대상자들의 특성은 Table 1과 같다.

\section{2. 연구 설계}

본 연구는 단일 사례 연구(single subject experimental design)로 $\mathrm{ABA}$ 디 자인을 사용하였으며, 기초선 단계(baseline phase), 중재 단계(intervention phase) 그리고 다시 기초선 회귀 단계(follow up phase)로 나누어 진 행하였다. 초기 기초선 단계에서는 중재 없이 기초 호흡기능 자료를 측정하였고, 중재 단계에서는 보이타 중재를 실시한 이후 치료 결과 를 측정하였으며, 4 주 후 기초선 회귀 단계를 두었다. 보이타 중재는 대 상자의 시간을 고려하여 7주간 주 3-4회 실시하였으며, 1 일 1회로 1회 실시 시 좌우측 교대로 5 분씩 20 분간 총 25 회 실시하였다. 기초선은 한 번씩 3 일 동안 측정하여 안정된 자료를 확인 후 설정하였으며, 중재 종료 후와 기초선 회귀 단계에서 한 번씩 측정하였다(Figure 1).

\section{3. 측정 장비 및 방법}

\section{1) 폐활량 측정기(spirometer)}

본 연구에서는 연구 대상자의 심폐 기능을 측정하기 위해서 폐활량 측정기(Spirometer Cosmed PONY, Italy)를 사용하였다(Figure 2). 연구

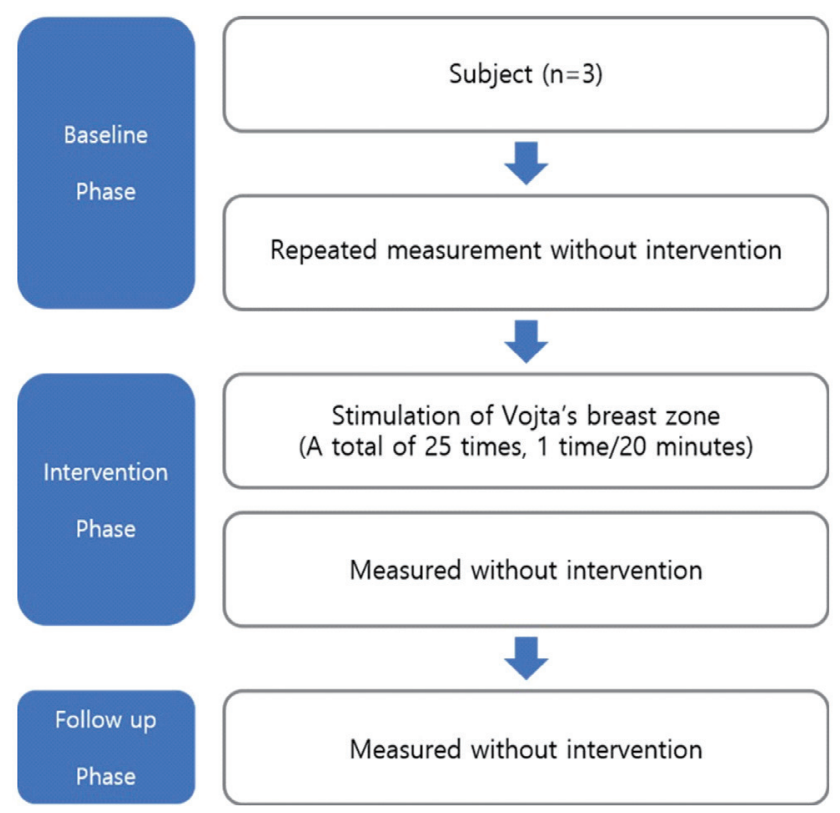

Figure 1. Flow chart.

Table 1. Characteristics of the subjects

\begin{tabular}{lcccccc}
\hline & Gender & Age & Height $(\mathrm{cm})$ & Weight $(\mathrm{kg})$ & $\begin{array}{c}\text { Smoking duration } \\
\text { (yr) }\end{array}$ & $\begin{array}{c}\text { Quantity of cigarettes } \\
\text { smoked per day }\end{array}$ \\
\hline Subject 1 & Male & 24 & 167 & 57 & 5 & 10 \\
Subject 2 & Male & 24 & 167 & 67 & 9 & 14 \\
Subject 3 & Male & 21 & 180 & 105 & 7 & 15 \\
\hline
\end{tabular}


자는 대상자들에게 측정 전 충분한 검사 방법에 대해 교육한 이후에 측정하였다. 본 연구에서 사용한 폐활량 측정기는 간편하게 폐 기능 이나 폐 환기량을 볼 수 있는 일반적인 도구이다. 본 연구는 폐활량 측정기를 이용해 폐 기능 검사 지표들 가운데 FVC와 FEV1을 측정하 였다. $\mathrm{FVC}$ 는 가능한 최대로 공기를 들이마시고 난 이후 최대한 빠르 고 세게 불어 낸 공기의 양을 뜻하며, ${ }^{21} \mathrm{FEV1}$ 은 최대한 깊이 공기를 들 이마신 이후 최대한 빠르고 세게 공기를 불어 내보내는 공기의 양 중 처음 1 초간 빠져나간 공기의 양을 의미한다. ${ }^{22}$

측정 방법은 대상자는 코 집게를 착용하고 벽에 기대앉은 자세에 서 상체가 앞으로 굽혀지지 않도록 하였으며, 측정 이전에 숨을 편하 게 내쉰 이후에 날숨의 시작 전 전폐용량까지 완전히 들이마신 후 노 력성 날숨이 최대한으로 이뤄지도록 하였다. 검사 중 마우스피스 주 위로 바람이 새지 않도록 주의시켰다. 측정값은 3회 실시하였으며, 1 회 실시 후 30 초간 휴식을 가졌고, 실시한 값 사이에서 최대치를 선택 하였다.

\section{2) 중재 프로그램}

본 연구에서 중재는 보이타 치료 연수를 받은 지도 교수의 감독하에 한 명의 학생이 실시하였으며, 보이타 중재 적용 전 4 주간 교육 후 대상 자를 제외한 한 명의 학생을 대상으로 예비 실험을 진행하였다. 대상

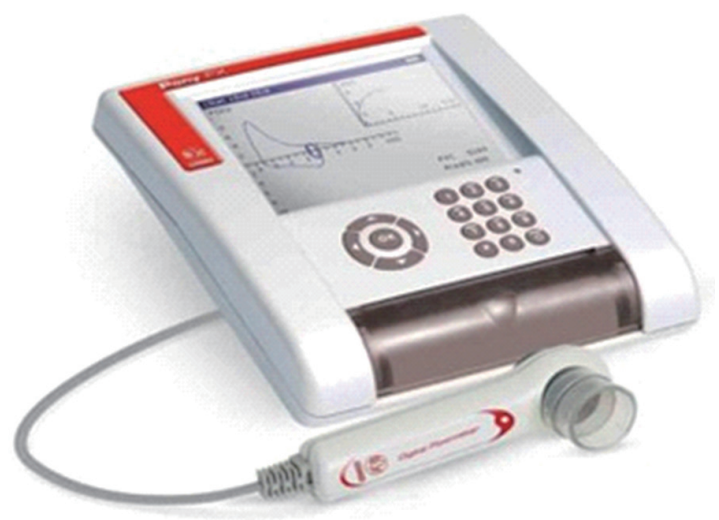

Figure 2. Spirometer.

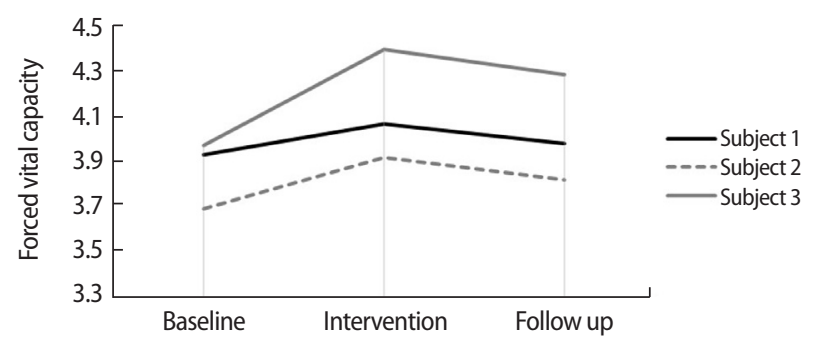

Figure 3. The comparison of forced vital capacity form each period.
자는 편안하게 바로 누운 자세에서 고개를 $30^{\circ}$ 돌린 쪽을 얼굴 측으로 설정하였으며, 얼굴 측 갈비뼈 6-7번 또는 7-8번 사이의 갈비뼈 사이 공 간(intercostal space)을 가슴 유발점으로 설정하였다. 자극의 방향은 머 리 쪽, 안쪽, 등 쪽의 벡터 합성 방향인 뒤통수 쪽 어깨 방향으로 향하 도록 하였다. 좌우측 각각 5 분씩 교대로 총 20 분 실시하였다.

\section{4. 자료 처리}

기초선, 중재 그리고 중재 후 기초선 회귀 기간 동안 자료의 안정성과 변화를 비교하기 위하여 그래프와 기술 통계량을 이용한 시각 분석 법(visual analysis)을 사용하였다.

\section{결 과}

\section{1. 각 시기별 노력성 폐활량(FVC) 비교}

$\mathrm{FVC}$ 결과는 Figure 3 에 제시하였다. 대상자 1 은 기초선 단계에서 평균 $3.94 \mathrm{~L}$ 였으나 중재 단계에는 $4.08 \mathrm{~L}$ 로 증가하였으며, 기초선 회귀 단계 에서는 $3.99 \mathrm{~L}$ 로 감소하였으나 기초선 단계보다 높은 값을 유지하였 다. 대상자 2는 기초선 단계에서 평균 $3.7 \mathrm{~L}$, 중재 단계는 $3.93 \mathrm{~L}$ 로 증가 하였으며, 기초선 회귀 단계에서는 $3.83 \mathrm{~L}$ 로 감소하였으나 기초선 단계 보다 높은 값을 유지하였다. 대상자 3 은 기초선 단계에서 평균 $3.98 \mathrm{~L}$, 중재 단계는 $4.41 \mathrm{~L}$ 로 증가하였으며, 기초선 회귀 단계에서는 $4.30 \mathrm{~L}$ 로 감소하였으나 기초선 단계보다 높은 값을 유지하였다(Figure 3).

\section{2. 각 시기별 1 초간 노력성 호기량(FEV1) 비교}

FEV1 결과는 Figure 4에 제시하였다. 대상자 1은 기초선 단계에서 평 균 $3.20 \mathrm{~L}$ 였으나 중재 단계에는 $3.44 \mathrm{~L}$ 로 증가하였으며, 기초선 회귀 단 계에서는 $3.20 \mathrm{~L}$ 로 기초선 단계와 동일하였다. 대상자 2 는 기초선 단 계에서 평균 $3.12 \mathrm{~L}$, 중재 단계는 $3.33 \mathrm{~L}$ 로 증가하였으며, 기초선 회귀 단계에서는 $3.32 \mathrm{~L}$ 로 중재 기간의 값을 유지하였다. 대상자 3 은 기초 선 단계에서 평균 $3.52 \mathrm{~L}$, 중재 단계는 $3.59 \mathrm{~L}$ 로 증가하였고, 기초선 회 귀 단계에서는 $3.59 \mathrm{~L}$ 로 중재 기간의 값을 유지하였다(Figure 4).

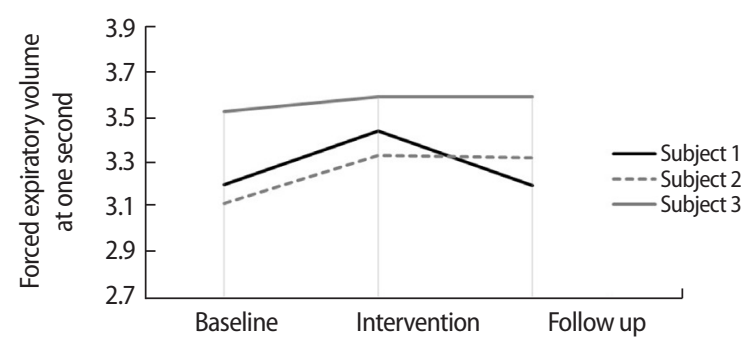

Figure 4. The comparison of forced expiratory volume at one second from each period. 


\section{고 찰}

흡연은 폐 질환, 호흡기 질환들을 일으키는 주요 원인으로, ${ }^{11,23}$ 그중 $\mathrm{COPD}$ 환자들은 안정 시 호흡과 폐활량의 감소를 보이며, ${ }^{6}$ 이로 인한 호흡곤란은 활동량 감소와 함께 호흡근의 약화를 초래한다.7.8

보이타 치료는 일반적으로 뇌성마비 아동의 운동 기능 손상을 개 선시키고자 하는 목적으로 적용되었으며, ${ }^{24}$ 이에 따른 결과로 자세 조 절과 호흡 근육의 활성화 및 들숨 시 가로막의 근 활성을 보고하였 다.25,26 최근 많은 임상 연구자들은 호흡 기능 향상을 위해 보이타 치 료를 적용하였으며, ${ }^{18-20,26}$ 뇌성마비 아동뿐만이 아닌 정상 성인을 대 상으로 보이타 치료를 적용한 논문이 보고되고 있다. ${ }^{27}$ 따라서, 본 연 구에서는 젊은 흡연 남성을 대상으로 보이타 치료를 적용하여 $\mathrm{FVC}$ 와 FEVI의 변화를 알아보고자 하였다.

본 연구 결과 대상자 모두 보이타 치료 후 FVC가 증가하였다. 노인 흡연인구를 대상으로 한 이전 연구에서 SPIROTIGER를 사용한 피드 백 호흡운동을 적용하여 배곧은근의 근 활성 증가를 나타냈으며 최 대 호기 속도와 $\mathrm{FVC}$ 의 증가를 보고하였다. ${ }^{28} \mathrm{FVC}$ 는 호흡근의 근력이 강하고 기도와 폐의 저항이 작을 때 증가한다고 하였다. ${ }^{21}$ 정상 성인 을 대상으로 보이타 가슴 유발점 자극을 적용한 선행 연구에서 배가 로근의 두께와 들숨 시 가로막 면적의 유의한 증가를 보고하였다. ${ }^{26}$ 또한, 뇌성마비 아동을 대상으로 적용한 결과 배바깥빗근 및 배곧은 근의 근 활성과 $\mathrm{FVC}$ 의 향상을 보고하였고, ${ }^{20}$ 들숨 시 가로막의 근 활 성을 보고하였다. ${ }^{26}$ 본 연구에서 호흡 기능 개선을 위해 적용한 보이 타의 중재는 다른 질환 대상자에게 적용한 보이타 중재 결과와 동일 한 결과를 도출하였다. ${ }^{20}$ 들숨 시 가로막의 수축은 가슴우리를 측방 으로 팽창시켜 가로막의 면적 증가를 야기하여 들숨을 촉진한다. ${ }^{29}$ 반대로 노력성 날숨 시 복부 근육 특히, 배가로근의 수축은 복부 내 압을 증가시키고 이완된 가로막을 위쪽으로 강하게 밀어 올리게 한 다. ${ }^{29}$ 따라서, 본 연구에서 $\mathrm{FVC}$ 의 증가는 보이타 치료의 가슴 유발점 자극을 통해 들숨 시 가로막을 활성화시키고 날숨 시 복부 근육 특 히, 배가로근의 수축을 촉진시킨 결과로 사료된다.

본 연구에서 FEV1 결과는 대상자 모두 보이타 치료 후 증가하였다. 선행연구에서 경증 $\mathrm{COPD}$ 환자에게 호흡근 근력 강화 훈련으로 SPIROTIGER를 사용한 피드백 호흡 운동을 적용하여 1 초간 노력성 호 기량과 배곧은근의 근 활성 증가를 보고하였다. ${ }^{13} \mathrm{Kang}$ 등 ${ }^{30}$ 은 경직형 뇌성마비 아동을 대상으로 호흡운동을 적용하여 가로막의 자발적 호흡 수축의 크기와 호흡 근력의 증가를 보고하였으며, 이러한 요인 들이 FEV1의 향상을 가져왔다고 설명하였다. 경직형 뇌성마비 아동 을 대상으로 보이타 치료를 적용한 연구 결과 배바깥빗근 및 배곧은 근의 근 활성 증가와 $\mathrm{FEV} 1$ 의 향상을 보고하였다. ${ }^{20} \mathrm{FEV} 1$ 은 기도 폐쇄 정도를 객관적으로 평가하는 대표적인 방법이며, ${ }^{31} \mathrm{FEV}$ 의 감소는 전
체적인 활동량의 감소를 야기하고 이로 인해 호흡곤란을 더욱 악화 시킨다. ${ }^{32}$ 날숨은 정적 호흡에서 수동적인 과정이나 노력성 날숨 시에 는 복부 근육이 수축되어 복부 내압 증가와 가로막의 상방 이동이 나 타난다. ${ }^{33,34}$ 선행연구에 따르면, 느린 날숨을 동반한 전통적인 복부 Curl-up 운동 시 배가로근과 배속빗근의 근 활성을 증가시켰다고 보 고하였다. ${ }^{35}$ 이와 함께, 가로막은 복부 근육과 함께 체간 조절에 영향 을 준다고 하였다. ${ }^{36}$ 또한, $\mathrm{Ha}$ 와 Sung ${ }^{26}$ 은 보이타 가슴 유발점 자극으 로 가로막의 움직임을 나타냈으며, 가로막이 호흡과 자세 유지에 관 여한다고 하였다. ${ }^{27}$ 따라서, 보이타 치료는 호흡에 직접적으로 관여하 는 가로막을 활성화시켜 자세 조절과 호흡 근육을 활성화시킨다고 할 수 있다. Giannantonio 등 25 은 보이타 치료가 자세 조절과 호흡 근 육을 활성화시켜 뇌성마비 아동의 호흡 능력과 운동 발달을 개선시 키는 효과적인 치료방법이라고 제시하였다.Cho와 Lee ${ }^{37}$ 는 뇌졸중 환 자에게 호흡 기구 운동 훈련과 호흡 운동을 적용한 결과 호흡근의 협 응력과 근력이 증가해 호흡 기능의 향상으로 $\mathrm{FEV1}$ 이 증가되었다고 보고하였다. 따라서 본 연구에서 FEV1의 증가는 보이타 치료의 가슴 유발점 자극을 통해 가로막 및 복부 근육의 근 활성과 호흡근들의 협 응력을 증가시키고 호흡 기능을 증가시킨 결과로 사료된다.

이상의 결과를 종합해 볼 때 호흡 근육의 힘이 세고 기도와 폐의 저항이 작을 때 증가하는 $\mathrm{FVC}^{21}$ 와 기도 폐쇄 정도를 평가하는 데 적 합한 $\mathrm{FEV1} 1^{31}$ 이 보이타 치료 후 모두 향상되었다. 따라서, 보이타의 가 슴 유발점 자극은 흡연 인구의 기도 폐쇄 정도를 호전시키고, 가로막 과 복부 근육을 활성화시켜 호흡기능을 향상시킬 수 있는 중재 방법 이라고 할수 있다.

본 연구의 제한점은 다음과 같다. 먼저, 본 연구는 3 명의 흡연 남성을 대상으로 실시한 단일 사례연구로서 대상자 수가 적어 연구결과의 일 반화가 어렵다. 또한 흡연 남성의 호흡 능력 향상에 미치는 영향을 알 아보고자 하였으나 대조군 없이 진행되었다. 다음으로, 중재 기간 동안 실험에 영향을 미칠 수 있는 대상자의 일상생활을 철저히 통제하지 못 하였다. 마지막으로, 보이타 치료 연수를 받은 지도 교수의 감독하에 한 명의 학생이 진행하여 치료 결과가 경험이 풍부한 전문가들과 다를 수 있다. 향후 연구에서는 대조군을 설정하여 집단 실험 연구를 통해 흡연 인구에게 보이타 치료 적용 후 호흡 기능 향상의 효과를 검증할 수 있는 연구가 진행되어야 할 것으로 사료된다. 또한 호흡 기능부전을 갖는 다양한 질환에 대한 보이타 치료 연구가 필요할 것으로 생각된다. 그럼에도 불구하고, 본 연구는 흡연 인구에게 보이타 치료를 적용하여 호흡 능력의 향상을 보고한 최초의 논문으로서 그 의미가 있다.

\section{결 론}

본 연구 결과, 흡연 인구에게 보이타 치료를 적용하였을 때 호흡 기능 
이 향상되어 $\mathrm{FVC}$ 와 $\mathrm{FEV1}$ 이 증가되었다. 이러한 결과는 보이타 치료 가 호흡 기능에 제한이 있는 흡연 인구 및 다양한 호흡기 질환자에게 추천될 수 있는 중재 방법이라고 사료된다.

\section{REFERENCES}

1. Roh HL, Lee DH. Respiratory function of university students living at high altitude. J Phys Ther Sci. 2014;26(9):1489-92.

2. Ho CSH, Tan ELY, Ho RCM et al. Relationship of anxiety and depression with respiratory sympto ms: Comparison between depressed and non-depressed smokers in singapore. Int J Environ Res Public Health. 2019;16(1):1-13.

3. Hall JE, Guyton AC, Brands MW. Pressure-volume regulation in hypertension. Kidney Int Suppl. 1996;55:35-41.

4. National Institute for Clinical Excellence. Depression: management of depression in primary and secondary care. London: NICE. 2004:1-16.

5. Morris JF, Temple W. Spirometric "lung age" estimation for motivating smoking cessation. Prev Med. 1985;14(5):655-62.

6. Simon KM, Carpes MF, Correa KS et al. Relationship between daily living activities (ADL) limitatio $\mathrm{n}$ and the BODE index in patients with chronic obstructive pulmonary disease. Rev Bras Fisioter. 2011;15(3):212-8.

7. Dahlen I, Janson C. Anxiety and depression are related to the outcome of emergency treatment in patients with obstructive pulmonary disease. Chest. 2002;122(5):1633-7.

8. Olopade CO, Beck KC, Viggiano RW et al. Exercise limitation and pulmonary rehabilitation in chronic obstructive pulmonary disease. Mavo Clin Proc. 1992;67(2):144-57.

9. Roh SK, Choi YS. Effects of smoking on the physical fitness and cardiorespiratory function in university male students. KSSPE. 2013;18(2):231-8.

10. Sun SK, Jung DC, Ko KJ. The effects of chronic smoking on young male adult's cardiorespiratory function. KJSS. 2006;17(2):38-46.

11. Cha KS. A comparison of pulmonary function, aerobic power, blood pressure, blood hemoglob in smokers and non-smokers. Phys Ther Korea. 2001;40(3):845-57.

12. Tantisuwat A, Thaveeratitham P. Effects of smoking on chest expansion, lung function, and respiratory muscle strength of youths. J Phys Ther Sci. 2014;26(2):167-70.

13. Kang JI, Jeong DK, Choi H. The effect of types of respiratory exercise on respiratory muscle activity and health-related quality of life of patients with severe chronic obstructive pulmonary disease. J Kor Phys Ther. 2016;28(1):46-51

14. Jung HJ, Lee DT. Impact of concurrent inspiratory muscle and aerobic exercise training on pulmonary function and cardiopulmonary responses. Exerc Sci 2012:21(3):373-84.

15. Hok P, Opavsky J, Kutin M et al. Modulation of the sensorimotor system by sustained manual pressure stimulation. Neuroscience. 2017;348:11-22.

16. Sanz-Esteban I, Calvo-Lobo C, Rios-Lago M et al. Mapping the human brain during a specific Vojta's tactile input: the ipsilateral putamen's role. Medicine. 2018;97(13):1-9.

17. Mori RL, Bergsman AE, Holmes MJ et al. Role of the medial medullary reticular formation in relaying vestibular signals to the diaphragm and abdominal muscles. Brain Res. 2001;902(1):82-91.
18. Sohn JS. The effects of Vojta therapy on respiratory function, arterial oxygen saturation, chest cavity volume in children with cerebral palsy. Korea National Sport University. Dissertation of Master's Degree. 2016.

19. Song CH, Kim HJ. The Effect of Vojta's Reflex forward movement on the ontogenesis spontaneous pathologic locomotion, vital capacity, hand function, balance and gait in children with spasticity cerebral palsy. Journal of Special Education \& Rehabilitation Science. 2010;49(1):89-111.

20. Lee HJ, Joo GC. The effects of Vojta's reflex locomotion movement on respiratory capacity in children with spastic cerebral palsy. Journal of Special Education \& Rehabilitation Science. 2014;53(1):235-59.

21. Cho DK, Park HM. Acute effect of cigarette smoking on pulmonary function. Korean J Intern Med. 1981;24(9):757-65.

22. Byun SH, Han DW. The Effects of passive stretching exercise of the scalene muscles on forced vital capacity. J Korean Soc Phys Med. 2016;11(1):35-43.

23. Taghizadeh N, Vonk JM, Boezen HM. Lifetime smoking history and cause-specific mortality in a cohort study with 43 years of follow-up. PLoS One. 2016;11(4):1-18.

24. Lim HW, Kim TH. Effects of Vojta therapy on gait of children with spastic diplegia. J Phys Ther Sci. 2013;25(12):1605-8.

25. Giannantonio C, Papacci P, Ciarniello R et al. Chest physiotherapy in preterm infants with lung diseases. Ital J Pediatr. 2010;36(1):65-9.

26. Ha SY, Sung YH. Effects of Vojta approach on diaphragm movement in children with spastic cerebral palsy. J Exerc Rehabil. 2018;14(6):1005-9.

27. Ha SY, Sung YH. Effects of Vojta method on trunk stability in healthy individuals. J Exerc Rehabil. 2016;12(6):542-47.

28. Jun HJ, Kim KJ, Nam KW. Effects of breathing exercises on lung capacity and muscle activities of elderly smokers. J Phys Ther Sci. 2016;28(6):16815.

29. Yoo TW, Kang SW, Moon JH et al. Change in forced vital capacity with postures according to neuromuscular disease. ARM. 2006;30(1):80-5.

30. Kang MS, Shim JH, Kang SY. Comparisons of diaphragm movement, pulmonary function, and pulmonary strength among exercise methods in children with cerebral palsy. J Kor Phys Ther. 2018;13(1):121-8.

31. Burns KL. An evaluation of two inexpensive instruments for assessing airway flow. Ann Allergy. 1979;43(4):246-9.

32. Casaburi R, Wasserman K, Patessio A et al. A new perspective in pulmonary rehabilitation: anaerobic threshold as a discriminant in training. Eur Respir J. 1989;7(2):618-23.

33. Campbell EJ, Green JH. The expiratory function of the abdominal muscles in man; an electromy ographic study. J Physiol. 1953;120(3):409-18.

34. Woorons X, Mollard P, Pichon A et al. Prolonged expiration down to residual volume leads to severe arterial hypoxemia in athletes during submaximal exercise. Respir Physiol Neurobiol. 2007;158(1):75-82.

35. Yoon TL, Kim KS, Cynn HS. Slow expiration reduces sternocleidomastoid activity and increases transversus abdominis and internal oblique muscle activity during abdominal curl-up. J Electromyo gr Kinesiol. 2014;24(2):228-32.

36. Kim SH, Park SY. Effect of hip position and breathing pattern on abdominal muscle activation during curl-up variations. J Exerc Rehabil. 2018;14(3):445-50.

37. Cho YH, Lee SB. Impact of respiratory muscle exercises on pulmonary function and quality of sleep among stroke patients. J Korean Soc Phys Meds. 2015;10(4):123-31. 